\title{
URINARY TRACT INFECTIONS AFTER RENAL TRANSPLANTATION: IS MALE GENDER A RISK FACTOR FOR RESISTANT AND RECURRENT INFECTIONS?
}

\author{
Gokhan Guneri ${ }^{1}$, Arzu Velioglu ${ }^{1}$, Hakki Arikan ${ }^{1}$, Ebru Asicioglu${ }^{1}$, Yiloren Tanidir ${ }^{1}$, Ilker \\ Tinay $^{1}$, Cumhur Yegen ${ }^{1}$, and Serhan Tuglular ${ }^{1}$ \\ ${ }^{1}$ Marmara University School of Medicine
}

October 22, 2020

\begin{abstract}
Background: The most common infections among renal transplant patients are urinary tract infections (UTI). Our main objective in this study is to determine the incidence of UTIs in patients who have undergone renal transplantation in our hospital, to identify the causative microbiological agents, risk factors and determine the effects of UTI on short-term graft survival. Methods: Adult patients, who underwent renal transplantation between October 2011 and July 2018, were included in this study. Urinary tract infections which developed within the first year of renal transplantation were investigated. Patients were compared regarding demographic, clinical, laboratory characteristics, and graft survival. Results: 102 patients were included in our study. Forty patients $(51.9 \%)$ were male and 37 (48.1\%) were female. Sixty-seven urinary tract infection attacks in 21 patients were recorded. Age ( $\mathrm{p}=0.009 ; 95 \%$ Confidence Interval [CI]: 1.014-1.105), longer indwelling urinary catheter stay time ( $\mathrm{p}=0.027 ; 95 \%$ Confidence Interval [CI]: 1.010-1.174) and urologic complications ( $\mathrm{p}=0.032 ; 95 \%$ Confidence Interval [CI]: 0.094-0.896) were found as risk factors for UTI development in the first year of transplantation. Escherichia coli and Klebsiella pneumoniae were the most frequently isolated microorganisms. Of these bacteria, $63.2 \%$ were found to be extended spectrum beta lactamase (ESBL) positive. Resistant microorganisms were more frequent in male patients (31 episodes in males vs. 12 episodes in females, $\mathrm{p}=0.0015)$. UTI had no negative impact on short-term graft survival. Conclusion: Patients with advanced age, who had a longer duration of bladder catheterization and urologic complications should be followed carefully regarding UTI. Since there is a high incidence of UTI in male transplant patients, more frequently caused by resistant microorganisms, infection control methods should be applied more vigorously especially in male transplant patients.
\end{abstract}

\section{Introduction}

In kidney transplant recipients, the risk of infection is increased compared to the general population due to intensive immunosuppressive drug use, surgical procedures and environmental factors. The most common infections in renal transplant patients are urinary tract infections (UTI). The UTI rate in renal transplant patients has been reported to range between 20 to $80 \%$ [1-3].

Many different mechanisms and risk factors are responsible for the increased frequency of UTI in renal transplant patients. The most commonly reported risk factors are advanced age, female gender, diabetes mellitus, urinary system abnormality and previous history of urinary system infection. Deceased kidney transplantation, re-transplantation, neurogenic bladder dysfunction, vesicoureteral reflux, and in-dwelling urinary catheters also increase the risk of urinary tract infection. In addition, intensive immunosuppressive use after transplantation also contributes to the increased susceptibility to infections $[2,4,5]$.

The microorganisms that cause these infections seem to differ between countries and regions, but the most common causative microorganisms uniformly throughout the world are gram-negative bacteria. These are, 
in order of frequency, E. Coli (30-80\%), Klebsiella (10\%), Proteus (5\%) and Pseudomonas (5\%). Grampositive enterococci and Staphylococcus aureus are also more common in these patients compared to the general population [6-8]. Increasing prevalence of UTIs caused by multidrug-resistant microorganisms is one of the major challenges in transplant patients $[6,9,10]$. The latter situation makes UTI management more complex with increased need for hospitalization at higher costs.

The frequency of urinary tract infections may also differ between countries and centers considering the environmental, social and economic characteristics. Therefore, determining the frequency and risk factors of urinary tract infections in each transplantation population is very important for determining prevention and treatment strategies.

The aim of our study is to determine the incidence of urinary tract infections among our kidney transplant recipients, to determine the causative microorganisms as well as the underlying risk factors and to determine the impact of UTI on short-term graft survival.

\section{Patients-Methods}

Patients who underwent renal transplantation between October 2011 and July 2018 were included in the study. Patients younger than 18 years of age and patients with primary non-functioning kidney were excluded from the study. Urinary tract infections that developed in the first year after transplantation were examined retrospectively. Patients received a triple-drug immunosuppressive regimen typically consisting of calcineurin inhibitors (tacrolimus or cyclosporine), mycophenolate mofetil, and prednisone. Basiliximab was used as standard induction, while anti-thymocyte globulin was given to patients at high immunological risk. Corticosteroids were progressively tapered to $5 \mathrm{mg} /$ day over 3 months.

Antibiotic prophylaxis with single dose cefuroxime at a dose of $2 \mathrm{~g}$ was used in all patients before surgery. Ofloxacillin was administered after transplantation for 7 days. Trimethoprim/sulfamethoxazole was started for Pneumocystis Jiroveci prophylaxis was started on 7th day post transplant and continued for 6 months at a dose of $400 / 80 \mathrm{mg} /$ day. The ureteral stents placed during the transplant operation are removed at 6-8 weeks after transplantation, in the absence of active UTIs. Post-transplant urologic complications were defined as need for intermittent catheterization, bladder atony, need for surgical reconstruction of the urinary tract including ureteral necrosis, and ureteral and/or urethral strictures. [11]

UTI was defined as the presence of urine culture positivity with more than $10^{5}$ colony-forming units (CFU) of bacteria per $\mathrm{mL}$ with UTIs symptoms. A positive urine culture without any clinical symptoms was considered as asymptomatic bacteriuria (ABU). According to patients' clinical presentations, UTI attacks were divided into three groups: Lower UTI (LUTI), Complicated UTI (CUTI) and ABU (1). All patients with UTIs with ureteral stent were treated. Recurrent UTI was defined as [?] 3 UTIs in any 12-month period or [?]2 UTIs in any 6-month period, irrespective of the causative organism [12].

Extended spectrum beta-lactamase producing organisms (Escherichia coli, Klebsiella pneumoniae, Enterobacter spp., or Citrobacter spp.), Acinetobacter baumanii, methicillin-resistant Staphylococcus aureus, Enterococcus fecium, and Pseudomonas aeruginosa were considered as MDROs [13].

Patients were compared regarding the presence of at least one episode of UTI. This study was approved by the institutional review board (IRB approval number: 09.2017.429).

\section{Statistical Methods}

The characteristics of the study patients were expressed as mean or median, as appropriate for categorical variables, percentages and variables with continuity. Mann-Whitney U-test and Kruskal-Wallis test were used for comparing median variables between groups and independent samples $t$-test and one-way ANOVA tests were used for comparing parametric variables. For comparing categorical data, Chi-square and Fisher's exact test was used. Cox regression analysis was used to investigate the risk factors for the development of urinary tract infection. For all statistical analysis, $p$ value $<0.05$ was considered significant. All data are analyzed with SPSS (version 20.0; SPSS Inc, Chicago, IL) statistical package. 


\section{Results}

A total of 102 kidney transplant recipients were analyzed in this study. Forty-nine were women (48\%) and $53(52 \%)$ were men, with a mean age of $37,6 \pm 12,2$ years. The etiologic distribution of underlying primary kidney disease was as follows: primary glomerulonephritis (29/28.4\%), autosomal dominant polycystic kidney disease (ADPKD) $(6 / 5.8 \%)$, diabetic nephropathy $(9 / 8.8 \%)$, hypertensive nephropathy $(12 / 11.7 \%)$, others $(13 / 12.7 \%)$, and unknown etiology $(33 / 32.3 \%)$. Five patients had undergone second kidney transplantation. Seventy- seven $(75.5 \%)$ patients were on hemodialysis, $4(3.9 \%)$ were on peritoneal dialysis (PD), 7 patients were treated consecutively with both HD and PD (6.8\%) before the transplantation and $14(13.7 \%)$ patients underwent preemptive transplantation.

21 patients experienced at least one UTI over the study period and the incidence rate for a UTI was $20.5 \%$ across the whole cohort. A total of 67 UTI episodes were analyzed in the UTI group and the mean

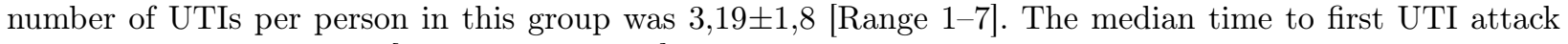
was calculated as 62 days [range 11-205 days] after transplantation. Presentations of 36 UTI episodes were LUTI, 23 were CUTI and 8 were ABU. Three patients (14,2\%) experienced UTI related bacteremia. Fortyseven episodes $(70,1 \%)$ were seen within the first six months of transplantation. The demographics and baseline characteristics of patients with and without UTI are shown in Table 1. In univariate analysis, age, dialysis vintage, foley catheter dwell time and presence of urologic complications were significantly different between the groups [Table 1]. In multivariate analysis age $(\mathrm{p}=0.009 ; 95 \%$ Confidence Interval [CI]: 1.0141.105), longer indwelling urinary catheter stay time $(\mathrm{p}=0.027 ; 95 \%$ Confidence Interval [CI]: 1.010-1.174) and urologic complications $(\mathrm{p}=0.032 ; 95 \%$ Confidence Interval $[\mathrm{CI}]: 0.094-0.896)$ were found as the main risk factors for UTI development in first year of transplantation.

The most common pathogen was Escherichia coli, isolated in 52 episodes $(77,6 \%)$, followed by Klebsiella spp. in $10(14,9 \%)$ whereas fungal species were found as causative agents in $3(4,4 \%)$ UTI episodes. In three UTI episodes, two different microorganisms were isolated. In total, 71 microorganisms were isolated in all patients. After excluding fungal causes, 43 out of 68 bacterial microorganisms $(63.2 \%)$ were caused by ESBL producing microorganisms. Details on UTI attacks, including causative agents, class of antibiotic used and treatment duration are summarized in Table 2.

Fifteen patients $(71.4 \%)$ ( 7 male/8 female) had at least one ESBL positive microorganism isolated as the causative agent of their UTI. Twelve patients (57.1\%) had recurrent UTI attacks while 6 of them (50\%) had recurrent UTI with MDROs. When we examined UTI episodes in detail, it was noteworthy to discover that male patients were more often infected with MDRO and had more recurrent UTIs when compared to female patients. The male recipients also had more CUTI at presentation compared with female recipients (Table $3)$.

In the analysis of fungal UTI episodes, all of them were resistant species and they were not accepted colonization even if they occurred while the patients still had ureteral stents. All in three patients required treatment with voriconazole or anidulafungin and all were treated successfully.

There was no impact of UTI even in recurrent patients, on short-term graft functions regarding creatinine levels.

\section{Discussion}

Post-transplant UTIs in kidney transplant patients are important causes of acute graft dysfunction. Increased morbidity and hospitalization rates are further major consequences of UTIs in kidney transplant recipients. Therefore understanding and exploring the UTI details is very crucial in transplant practice. In our study we found that UTI incidence in the first year after transplantation was 20.5\%. Although the incidence of UTI in kidney transplant recipients have been reported ranging between 7\%-80\% depending on the diagnostic criteria used, our UTI rate is relatively lower than reported in the other studies where the first year UTIs are evaluated $[1,4,14,15]$. In our study a lower rate of asymptomatic bacteriuria was found. The explanation for lower rate of $\mathrm{ABU}$ may be that a regular screening program was not used and urine culture studies were 
only performed in patients with UTI symptoms or pyuria in urinalysis observed during regular visits. Most patients with UTI attack presented as LUTI. CUTI incidence was found to be $34.3 \%$. Three attacks were progressed into bacteremia. The relatively mild course of UTI attacks might result from early detection and immediate antibiotic treatment in our cohort.

It has previously been reported that, early ( $<3$ weeks after transplantation) ureteric stent removal is associated with a lower rate of UTIs [16,17]. In our center we have not been followed this approach. Even though, presence of longer duration of ureteral stent was found in our cohort, we did not find higher rate of UTIs. Other factors such as, age, a longer duration of indwelling urinary catheter and presence of urologic complications, stood out as important risk factors in our patients. Thus, we recommend that patients with risk factors should be carefully screened for LUTI, CUTI and ABU.

The rates of UTI caused by ESBL-producing organisms were high in our cohort. More than half of UTI patients were exposed to at least one episode of UTI with MDROs. According to a recently published study from Australia, the authors isolated an ESBL-producing organisms in only 3,9\% of urine cultures [18]. Bodro et. al. demonstrated that 37\% of bacteria considered as MDROs in kidney transplant recipients' UTIs [10]. Nevertheless, there are some studies showing higher rates of UTI with MDROs in kidney transplant recipients similar to our findings $[19,20]$. This finding gave us the opportunity to explore our infection control methods and came to a conclusion that, prophylactic use of quinolones up to seven days postoperatively may be responsible from the high rate of UTIs with MDROs [11]. Changing our method of prophylaxis was the most important consequence of this study. We stopped prophylactic use of quinolones in our practice in line with study results.

There are many studies showing that urinary tract infections are more common in female recipients $[1,4,5]$. However, there are also some studies that did not find any difference with respect to gender [7, 22, 23]. Interestingly, in our study, we showed that recurrent urinary tract infections with resistant microorganisms are more common in male transplant recipients. Male recipients also presented more often with CUTI. Therefore, our data suggest, starting treatment with a wide-spectrum antibiotic may be warranted for UTI infections in male transplants since they tend to be caused by resistant microorganisms and have a tendency to recur. There are studies in both the general population and the transplant population to support these findings [24-27]. Urinary outflow obstruction, possible prostatitis, and inadequate response to antibiotics due to long uroepithelial tissue compared to women are the mechanisms that explain this situation.

It is important to emphasize that, a UTI caused by ESBL-producing microorganisms carries an almost three times greater risk of recurrence [6]. Brakemeir et al reported that recurrence rate of UTI with ESBL producing bacteria was found to be $54 \%$ [21]. Our findings were also consistent with this previously published data.

These results should be interpreted with caution due to the single center and retrospective nature of the study and the relatively small number of patients. The low number of events limits further statistical analysis for exploring exact effect of male gender on resistant and recurrent UTIs.

In conclusion, our results shed an interesting perspective on UTI in kidney transplant recipients. We strongly believe that each center should explore their own UTI risk factors and causative agents that will direct them to manage these patients correctly. This study also highlights the importance of monitoring causative agents of UTIs, especially in male gender, in order to improve empiric therapy in transplant practice.

\section{Conflict of interest}

The authors have declared that no conflict of interest exists.

\section{Acknowledgement}

The contents of this manuscript were presented as oral presentation at the 2018 American Transplant Congress (ATC) at the Washington State Convention Center, Seattle, WA, June 2 - 6th, 2018.

\section{References}


1. Goldman JD, Julian K. Urinary tract infections in solid organ transplant recipients: Guidelines from the American Society of Transplantation Infectious Diseases Community of Practice. Clin Transplant. 2019 ;33(9):e13507. doi: 10.1111/ctr.13507

2. Bodro M, Linares L, Chiang D, Moreno A, Cervera C. Managing recurrent urinary tract infections in kidney transplant patients. Expert Rev Anti Infect Ther. 2018; 16(9):723-732. doi: 10.1080/14787210.2018.1509708.

3. Kotagiri P, Chembolli D, Ryan J, Hughes PD, Toussaint ND. Urinary Tract Infections in the First Year Post-Kidney Transplantation: Potential Benefits of Treating Asymptomatic Bacteriuria. Transplant Proc. 2017; 49(9):2070-2075.

4. Ariza-Heredia EJ, Beam EN, Lesnick TG, Kremers WK, Cosio FG, Razonable RR. Urinary tract infections in kidney transplant recipients: role of gender, urologic abnormalities, and antimicrobial prophylaxis. Ann Transplant. 2013; 18: 195-204

5. Gozdowska J, Czerwińska M, Chabros E, et al. Urinary tract infections in kidney transplant recipients hospitalized at a transplantation and nephrology ward: 1-year follow-up. Transplant Proc. 2016;48(5):1580-1589

6. Michail Alevizakos, Dimitrios Nasioudis, Eleftherios Mylonakis. Urinary Tract Infections Caused by ESBL-producing Enterobacteriaceae in Renal Transplant Recipients: A Systematic Review and Meta-Analysis. Transpl Infect Dis. 2017;19(6). doi: 10.1111/tid.12759

7. Vidal E, Torre-Cisneros J, Blanes M, Montejo M, Cervera C, Aguado JM, Len O, Carratalá J, Cordero E, et al; Spanish Network for Research in Infectious Diseases (REIPI). Bacterial urinary tract infection after solid organ transplantation in the RESITRA cohort. Transpl Infect Dis. 2012;14(6):595-603

8. Parasuraman R, Julian K; AST Infectious Diseases Community of Practice. Urinary tract infections in solid organ transplantation. Am J Transplant. 2013;13 Suppl 4:327-36.

9. Pinheiro HS, Mituiassu AM, Carminatti M, Braga AM, Bastos MG. Urinary tract infection caused by extended-spectrum beta-lactamase- producing bacteria in kidney transplant patients. Transplant Proc. 2010; 42(2):486-487.

10. Bodro M, Sanclemente G, Lipperheide I, et al. Impact of antibiotic resistance on the development of recurrent and relapsing symptomatic urinary tract infection in kidney recipients. Am J Transplant. 2015;15(4):1021-1027.

11. Delmas-Frenette C, Dorais M, Tavares-Brum A, et al. Epidemiology and outcome of antimicrobial resistance to gram-negative pathogens in bacteriuric kidney transplant recipients. Transpl Infect Dis. 2017; 19(4): 10.1111/tid.12722. doi:10.1111/tid.12722

12. Britt NS, Hagopian JC, Brennan DC, et al. Effects of recurrent urinary tract infections on graft and patient outcomes after kidney transplantation. Nephrol Dial Transplant. 2017;32(10):1758-1766. doi:10.1093/ndt/gfx237

13. Magiorakos AP, Srinivasan A, Carey RB et al. Multidrug-resistant, extensively drug-resistant and pandrug-resistant bacteria: an international expert proposal for interim standard definitions for acquired resistance. Clin. Microbiol. Infect. 2012; 18: 268-81.

14. Naik AS, Dharnidharka VR, Schnitzler MA, et al. Clinical and economic consequences of first-year urinary tract infections, sepsis, and pneumonia in contemporary kidney transplantation practice. Transpl Int. 2016;29(2):241-252.

15. Gołębiewska JE, Dębska-Ślizień A, Rutkowski B. Urinary tract infections during the first year after renal transplantation: one center's experience and a review of the literature. Clin Transplant. 2014;28(11):1263-1270.

16. Visser IJ, van der Staaij JPT, Muthusamy A, Willicombe M, Lafranca JA, Dor FJMF. Timing of Ureteric Stent Removal and Occurrence of Urological Complications after Kidney Transplantation: A Systematic Review and Meta-Analysis. J Clin Med. 2019;8(5):689.

17. Cai JF, Wang W, Hao W, et al. Meta-analysis of Early Versus Late Ureteric Stent Removal After Kidney Transplantation. Transplant Proc. 2018;50(10):3411-3415.

18. Olenski S, Scuderi C, Choo A, et al. Urinary tract infections in renal transplant recipients at a quaternary care centre in Australia. BMC Nephrol. 2019;20(1):479. 
19. Kiros T, Asrat D, Ayenew Z, Tsige E. Bacterial urinary tract infection among adult renal transplant recipients at St. Paul's hospital millennium medical college, Addis Ababa, Ethiopia. BMC Nephrol. $2019 ; 20(1): 289$.

20. Yuan X, Liu T, Wu D, Wan Q. Epidemiology, susceptibility, and risk factors for acquisition of $\mathrm{MDR} / \mathrm{XDR}$ gram-negative bacteria among kidney transplant recipients with urinary tract infections. Infect Drug Resist. 2018;14(11):707-15.

21. Brakemeier S, Taxeidi SI, Zukunft B, et al. Extended-Spectrum Beta-Lactamase-Producing Enterobacteriaceae-Related Urinary Tract Infection in Kidney Transplant Recipients: Risk Factors, Treatment, and Long-Term Outcome. Transplant Proc. 2017;49(8):1757-1765.

22. Dantas SR, Kuboyama RH, Mazzali M, Moretti ML. Nosocomial infections in renal transplant patients: risk factors and treatment implications associated with urinary tract and surgical site infections. J Hosp Infect. 2006;63(2):117-123. doi:10.1016/j.jhin.2005.10.018

23. Bodro M, Sanclemente G, Lipperheide I, et al. Impact of urinary tract infections on short-term kidney graft outcome. Clin Microbiol Infect. 2015; 21(12):1104.e1-1104.e11048.

24. Pilmis B, Scemla A, Join-Lambert O, et al. ESBL-producing enterobacteriaceae-related urinary tract infections in kidney transplant recipients: incidence and risk factors for recurrence. Infect Dis (Lond). 2015;47(10):714-718.

25. Bischoff S, Walter T, Gerigk M, Ebert M, Vogelmann R. Empiric antibiotic therapy in urinary tract infection in patients with risk factors for antibiotic resistance in a German emergency department. BMC Infect Dis. 2018;18(1):56.

26. Almomani BA, Hayajneh WA, Ayoub AM, Ababneh MA, Al Momani MA. Clinical patterns, epidemiology and risk factors of community-acquired urinary tract infection caused by extended-spectrum beta-lactamase producers: a prospective hospital case-control study. Infection. 2018;46(4):495-501.

27. Briongos-Figuero LS, Gómez-Traveso T, Bachiller-Luque P, et al. Epidemiology, risk factors and comorbidity for urinary tract infections caused by extended-spectrum beta-lactamase (ESBL)-producing enterobacteria. Int J Clin Pract. 2012;66(9):891-896.

Table 1. Demographic and clinical data in patients with or without urinary tract infections (UTI)

\begin{tabular}{|c|c|c|c|}
\hline & $\mathrm{UTI}(+) \mathrm{n}=21$ & $\operatorname{UTI}(-) \mathrm{N}=81$ & $p$ value \\
\hline Age (years) & $45,6 \pm 13,1$ & $35,5 \pm 11,1$ & $0.003^{*}$ \\
\hline Sex (female/male) & $14 / 7$ & $35 / 46$ & 0.085 \\
\hline $\begin{array}{l}\text { Dialysis Vintage } \\
\text { (median, months) }\end{array}$ & 8 & 45 & $0.002^{*}$ \\
\hline Previous tx $(\mathrm{n})$ & 0 & 5 & 0.581 \\
\hline $\begin{array}{l}\text { Preemptive } \\
\text { transplantation (n) }\end{array}$ & 2 & 12 & 0.729 \\
\hline Living/deceased )n) & $3 / 18$ & $19 / 62$ & 0.553 \\
\hline $\begin{array}{l}\text { Donor sex } \\
\text { (female/male) }\end{array}$ & $12 / 9$ & $52 / 29$ & 0.551 \\
\hline Donor age (years) & $47,8 \pm 10,9$ & $45 \pm 11,3$ & 0.325 \\
\hline Induction (n) & $11 / 10$ & $58 / 23$ & 0.118 \\
\hline DM or PTDM (n) & 8 & 23 & 0.430 \\
\hline $\begin{array}{l}\text { Hospitalization } \\
\text { duration at } \\
\text { transplantation (days) }\end{array}$ & $12,8 \pm 9,8$ & $8,9 \pm 3,2$ & 0.091 \\
\hline $\begin{array}{l}\text { Urinary catheter dwell } \\
\text { time (days) }\end{array}$ & $10,9 \pm 7,3$ & $6,9 \pm 1,4$ & $0.02^{*}$ \\
\hline Double J stent (days) & $64,1 \pm 27,1$ & $53,4 \pm 16,4$ & 0.096 \\
\hline $\begin{array}{l}\text { Urologic complications } \\
\text { after transplantation } \\
\text { (n) }\end{array}$ & 6 & 2 & $0.001 *$ \\
\hline
\end{tabular}




\begin{tabular}{llll}
\hline & UTI $(+) \mathrm{n}=21$ & UTI $(-) \mathrm{N}=81$ & $p$ value \\
\hline DGF $(\mathrm{n})$ & 5 & 7 & 0.120 \\
$\begin{array}{l}\text { Rejection }(\mathrm{n}) \\
\text { Creatinine at } 1^{\text {st }}\end{array}$ & 7 & 19 & 0.403 \\
$\begin{array}{l}\text { month }(\mathrm{mg} / \mathrm{dL}) \\
\text { Creatinine at } 1^{\text {st }} \text { year }\end{array}$ & $1,21 \pm 0,6$ & $1,25 \pm 0,4$ & 0.623 \\
$\begin{array}{l}\mathrm{mg} / \mathrm{dL}) \\
\begin{array}{l}\text { Creatinine at } 2^{\text {nd }} \text { year } \\
(\mathrm{mg} / \mathrm{dL})\end{array}\end{array}$ & $1,07 \pm 0,32$ & $1,12 \pm 0,4$ & 0.977 \\
\hline
\end{tabular}

DM, diabetes mellitus; PTDM, post-transplant diabetes mellitus; DGF, delayed graft function.

Table 2. Causative agents and treatment choices for UTI during the first year of transplantation (71 agents in total 67 UTI attack)

\begin{tabular}{ll}
\hline Microorganisms & $\mathrm{n}$ \\
\hline E. coli (attack/patients) & 5233 \\
ESBL (+) & \\
Klebsiella & \\
ESBL (+) & \\
Enterococcus feacalis* & \\
Staph epidermidis & \\
Candida glabrata & \\
Candida tropicalis & \\
& 1210 \\
& 3 \\
Treatments** & 1 \\
Penicillins & $\mathrm{n} 1$ \\
Cephalosporins & 21111243331235 \\
Fosfomycin & \\
Ciprofloxacin & \\
Nitrofurantoin & \\
Carbapenems & \\
Ertapenem & \\
Meropenem & \\
Antifungals & \\
No treatment*** & \\
Treatment duration (days, mean) & $9,2 \pm 4$ \\
\hline
\end{tabular}

$*_{\text {isolated with other bacteria }}^{* *}$ four patients were treated with two class of antibiotics ${ }^{* * *}$ patients with asymptomatic bacteriuria ESBL, Extended spectrum beta-lactamase.

Table 3. Comparison of male and female patients with UTI

\begin{tabular}{llll}
\hline & Male $(\mathrm{n}=7)$ & Female $(\mathrm{n}=14)$ & $\mathrm{p}$ \\
\hline Age (years) & $46,5 \pm 11,5$ & $45,1 \pm 14,2$ & 0.808
\end{tabular}




\begin{tabular}{|c|c|c|c|}
\hline & Male $(\mathrm{n}=7)$ & Female $(\mathrm{n}=14)$ & $\mathrm{p}$ \\
\hline $\begin{array}{l}\text { Dialysis vintage } \\
\text { (months) (median) }\end{array}$ & 60 & 42 & 0.930 \\
\hline Living/Deceased (n) & $6 / 1$ & $12 / 2$ & 0.659 \\
\hline $\begin{array}{l}\text { Induction (ATG) (n) } \\
(\%)\end{array}$ & $4(57.1)$ & $6(42.8)$ & 0.536 \\
\hline $\mathrm{DM}$ or PTDM $(\mathrm{n})(\%)$ & $4(57.1)$ & $4(28.6)$ & 0.346 \\
\hline Double J stent (days) & $60,7 \pm 17$ & $65,8 \pm 31,4$ & 0.633 \\
\hline $\begin{array}{l}\text { Indwelling urinary } \\
\text { catheter (days) }\end{array}$ & $13,3 \pm 6,8$ & $9,7 \pm 7,5$ & 0.056 \\
\hline $\begin{array}{l}\text { Urologic complication } \\
\text { (n) }(\%)\end{array}$ & $3(42.8)$ & $3(21.4)$ & 0.354 \\
\hline Total UTI episodes & 34 & 33 & 0.108 \\
\hline Mean UTI episodes & 4,85 & 2,35 & $0.002^{*}$ \\
\hline $\begin{array}{l}\text { Clinical Presentations (n) } \\
\text { (\%) CUTI } \\
\text { LUTI } \\
\text { ABU }\end{array}$ & $\begin{array}{l}15(44.1) 12(35.3) 7 \\
(20.6)\end{array}$ & $8(24.2) 24(72.7) 1(3)$ & $0.005^{*}$ \\
\hline $\begin{array}{l}\text { Microorganisms Bacteria } \\
\text { Fungal }\end{array}$ & 361 & 322 & 0.505 \\
\hline $\begin{array}{l}\text { MDROs (episodes) (n) } \\
(\%)\end{array}$ & $31(86.1)$ & $12(37.5)$ & $0.015^{*}$ \\
\hline $\begin{array}{l}\text { Recurrent UTI } \\
\text { episodes (n) (\%) }\end{array}$ & $6(85.7)$ & $6(42.8)$ & $0.042^{*}$ \\
\hline $\begin{array}{l}\text { Recurrent UTI } \\
\text { episodes with MDRO } \\
\text { (n) }(\%)\end{array}$ & $5(71.4)$ & $1(7.1)$ & $0.006^{*}$ \\
\hline
\end{tabular}

DM, diabetes mellitus; PTDM, post-transplant diabetes mellitus; ATG, anti-thymocyte globulin. 